\title{
Effect of Sulfonation Temperature and Time on the Preparation of Methyl Ester Sulfonate Surfactant From Crude Palm Oil (CPO) Based Methyl Ester
}

\author{
Jaksen ${ }^{1, *}$ Idha Silviyati $^{1}$ Endang Supraptiah ${ }^{1}$ Rima Daniar $^{2}$ Elina Margaretty \\ ${ }^{1}$ Lecturer D3-Chemical Engineering Sriwijaya State Polytechnic, Palembang, Indonesia \\ ${ }^{2}$ Lecturer D4- Energy Engineering, Sriwijaya State Polytechnic, Palembang, Indonesia \\ *Corresponding author.Email: Jaksen@polsri.ac.id
}

\begin{abstract}
Research to study the effect of temperature and sulfonation time on the preparation of Methyl Ester Sulfonate (MES) surfactant using CPO-based Methyl Ester (ME) as raw material has been carried out. The temperature was varied 80 ${ }^{\circ} \mathrm{C}, 90{ }^{\circ} \mathrm{C}$ and $100{ }^{\circ} \mathrm{C}$; while the observation time is carried out every 1 hour to 4 hours. The sulfonating agent was used $\mathrm{Na}_{2} \mathrm{~S}_{2} \mathrm{O}_{5}$ where the mole ratio of $\mathrm{ME}$ and the agent was fixed, as well as the type and concentration of the catalyst. The experimental method was carried out in stages starting from sulfonation, bleaching, neutralization, filtering, drying MES, analysis and testing. The best experimental results were obtained at a temperature of $100{ }^{\circ} \mathrm{C}$ and a sulfonation time of 4 hours with the resulting MES characteristics, namely iodine number $16.92 \mathrm{~g}$ iod $/ \mathrm{g}$ sample, acid number $4.45 \mathrm{mg} \mathrm{KOH} / \mathrm{g}$ sample, surface tension 27.4 dyne / cm, and emulsion stability of 50.8 minutes. The best characteristics of Methyl Ester Sulfonate Acid (MES) are density $0.83-0.92 \mathrm{gr} / \mathrm{ml}$, viscosity $1.35-2.35 \mathrm{cp}$, and pH 2.26-4.68.
\end{abstract}

Keywords: CPO, Methyl Ester, Methyl Ester Sulfonate, Sulfonation, Surfactants

\section{INTRODUCTION}

Indonesia is one country that has a very large area of oil palm plantations. In 2004 the area of oil palm plantations in Indonesia was about 5 million hectares production 11.08 million tons per year. In Indonesia alone, crude oil producers of Crude Palm Oil (CPO) and Palm Kernel Oil (PKO) are the second largest producers in the world. However, in 2006 Indonesia has become the largest palm oil producer in the world.

Currently in Indonesia, palm oil is considered a fairly low product. So a change was made to increase the value of the product from palm oil by converting palm oil into surfactants, which is a product development downstream. Agro-industrial development that is more oriented toward the downstream is a strategy that must be implemented for several types of plantations that have the potential to be developed into export-oriented downstream products. According to Hambali et al. (2004), surfactants have added value almost eight times when compared to crude palm oil $\mathrm{CPO}$ and $\mathrm{PKO}$

Surfactants themselves are surface active ingredients that can be produced by chemical or biochemical synthesis. The main characteristic of surfactants is in their surface activity. Surfactants are able to increase the ability to reduce the surface and interface tension of a liquid, increase the formation of oil emulsions in water, change the speed of dispersed particle aggregation by inhibiting and reducing the flocculation and coalescence of dispersed particles so that the stability of the dispersed particles increases. Surfactants are also able to retain the bubbles or foam that forms longer (Bergenstahl, 1997).

In general, surfactants are synthesized from derivatives of petroleum and natural gas. However, the process of making surfactants from petroleum and natural gas can cause pollution to the environment. An alternative that can be taken is the use of vegetable oil as a raw material for making surfactants. Methyl ester sulfonate can also be synthesized from several plants such as coconut, crude palm oil (CPO) and Palm Kernel Oil (PKO), tallow and soybeans (Sheats and Arthur, 2002).

In large industries the sulfonation process is carried out using $\mathrm{SO}_{3}$ gas as a reactant. The advantages of $\mathrm{SO}_{3}$ gas as a sulfonating agent include being reactive, resulting in a more complete conversion, and there is no waste in the process.

However, this process requires expensive equipment and very strict controls because $\mathrm{SO}_{3}$ gas has 
high reactivity and results in a black product. For further application, the black product color requires a bleaching process. Sodium Bisulfite $\left(\mathrm{NaHSO}_{3}\right)$ can be used because it has the advantage that the resulting product is brighter in color and easy to apply on a small product scale. Hidayati, Sri et al. Conducted research on the use of sodium bisulfite as a reactant in the process of making MES. (2012), Helianty and Zulfansyah. (2011).

Surfactants or surface active agents are active compounds that can reduce surface tension and interface tension which can be produced through chemical or biochemical synthesis. Surfactants are ampiphilic, namely compounds that have two groups with different properties in one molecule, namely hydrophilic and lipophilic groups so that they are able to unite two materials with different polarity.

Sugihardjo et al. (2002), stated that the factors that affect the effectiveness of surfactants in reducing the oil-water interface tension are the type of surfactant used, the surfactant and co-surfactant concentration, while according to Gomma. (1997), microemulsion stability is influenced by salinity, additives, hardness, temperature and pressure.

The types of surfactants that are most widely used are surfactants of the anionic and nonionic types. According to the Central Statistics Agency (2010), industry groups that use surfactants include the soap and cleaning industry $(85.93 \%)$, basic chemical industry $(4.64 \%)$, sheet plastic goods industry $(2.26 \%)$, sheet glass $(1.02 \%)$ and 34 other industrial groups (4.04\%). These surfactants are generally produced from petroleum so they are non-renewable and less friendly to the environment.

This research will discuss one of the vegetable surfactants, namely Methyl Ester Sulfonate (MES) Surfactant. Where this surfactant is made from palm oil. It should be noted that MES is the most environmentally friendly (environmentally friendly) of the anionic surfactants present in detergents. MES has good detergency properties even in small amounts, compared to other anionic surfactants, such as Linear Alkylbenzenesulfonates (LAS) and Alkyl Sulfates (US).

Surfactants can be synthesized from vegetable oils through compounds between fatty acid methyl esters and fatty alcohol (Sulastri, 2010). One of the processes to produce surfactants is the sulfonation process to produce MES. MES is an anionic surfactant, namely surfactants that have a negative charge on the hydrophilic group or the surface-active part.

The sulfonation process produces a derivative product in the form of a sulfate group reaction with oil, fatty acids, esters, and fatty alcohol. The type of oil that is usually sulfonated is oil that contains double bonds or hydroxyl groups on the molecule. Materials are rich in double bonds (Bernardini, 1983).

Preparation of methyl ester sulfonate (MES) surfactant using methyl ester as raw material through a sulfonation process which converts Fatty Acid methyl ester into MES surfactant. In this process, there are several factors that will determine the characteristics of the resulting product. These factors are the reaction temperature, neutralization time, type and concentration of $\mathrm{CaO}$ catalyst, $\mathrm{pH}$, concentration of added sulfonate groups $\left(\mathrm{Na}_{2} \mathrm{~S}_{2} \mathrm{O}_{5}\right)$ and neutralization temperature (Foster, 1996). Therefore, in this research, MES surfactant will be made from methyl ester with variations in temperature and reaction time to calculate the reaction kinetics of the sulfonation process based on the optimum temperature and time values.

In this study, there are several differences with previous studies, including the material used is CPObased metal esters where the CPO has been degummed, while previously many used PKO-based metal esters. Apart from that, the sulfonating agents used are $\mathrm{Na} 2 \mathrm{~S} 2 \mathrm{O} 5$ and $\mathrm{CaO}$ catalyst which are a new parameter in the sulfonation of metal esters to become metal ester sulfonate surfactants.

The aim of this research is to determine the optimum temperature and time for making MES in the sulfonation process. Be more specific to determine the effect of temperature and time on the analysis of acid number, iodine number, surface tension, and emulsion stability and finally to determine the effect of temperature on the analysis of MES surfactant compounds based on SNI 06-6989.51-2005.

\section{RESEARCH METHODOLOGY}

\subsection{Materials and Tools}

The main materials used in this study are: Methyl Ester, Aquadest, Methanol, Sodium Metabisulfite (Na2S2O5), Calcium Oxide ( $\mathrm{CaO})$, Sodium Hydroxide $(\mathrm{NaOH})$, and Hydrogen Peroxide (H2O2).

While the main equipment used is a four-neck flask, beaker, Buchner flask, hot plate, magnetic stirrer, pipette, reflux, condenser, pipette, anaitic balance, thermometer, tensiometer, viscometer, biuret equipment, pycnometer, stirrer motor, tool Other analyzes / tests.

\subsection{Experimental design}

1.

Sample Preparation Process

The methyl ester that has been obtained is precipitated beforehand to separate the heavy liquid and the light liquid. After that, weigh 435 grams $(500 \mathrm{ml})$ of methyl ester in 3 beaker containers to make it easier to carry out the sulfonation process.

\section{The Process of Making Methyl Ester Sulfonate}


A total of $500 \mathrm{ml}$ or 435 grams of methyl ester is added with a sulfonating agent, namely $\mathrm{Na}_{2} \mathrm{~S}_{2} \mathrm{O}_{5}$ with a ratio of 1 : 1.5 and $1 \% \mathrm{CaO}$ as a catalyst into a 4-neck flask to carry out the sulfonation process for 3 hours with a stirring speed of $500 \mathrm{rpm}$. This sulfonation process is carried out with variations in temperature and time, namely at temperatures of $80{ }^{\circ} \mathrm{C}, 90{ }^{\circ} \mathrm{C}$, and $100{ }^{\circ} \mathrm{C}$ for 1 hour, 2 hours, 3 hours, and 4 hours and the sulfonation results are transferred to a beaker for further processing. .

After the sulfonation process is complete, the methyl ester sulfonate is taken and transferred in a beaker for bleaching using chemical methanol 35\% and $\mathrm{H}_{2} \mathrm{O}_{2}$ while stirring at a speed of $300 \mathrm{rpm}$ and the temperature is maintained at $50{ }^{\circ} \mathrm{C}$ above the hotplate for 1.5 hours then methyl ester sulfonates are neutralized using $20 \% \mathrm{NaOH}$, stirring for 1 hour until the resulting $\mathrm{pH}$ is neutral or $\mathrm{pH} 7$. Finally, the methyl ester sulfonate was dried using a vacuum dryer until the MES which still contained the oil was separated from the oil and changed into a paste or granules.

\section{Results Analysis}

Analysis of the resulting MES product was carried out on density, viscosity (British Standard 757, 1975), $\mathrm{pH}$ testing (AOAC, 1995), acid number (SNI-013555-1998), Determination of Iodine Number (AOAC. 1995), surface tension ( BPMIGAS, 2009), emulsion stability (ASTM D 1436, 2001).

\section{RESULTS AND DISCUSSION}

\subsection{Effect of time and temperature on MES density}

Density or density is a measurement of the mass per unit volume. The higher the density of an object, the greater the mass per volume. The effect of temperature and sulfonation time on the density of the liquid cannot be neglected because the liquid will stretch with changes in temperature and sulfonation time. Density is generally associated with viscosity where the liquid is denser the higher the viscosity. This indicates that the content of the material affects its density. The measurement results show that MES has a density value of 0.83-0.92 gr / ml. The graph of the relationship between temperature and sulfonation time to MES density is presented in Figure 6. Overall the graph tends to be positive linear in the temperature range $80-100{ }^{\circ} \mathrm{C}$ and sulfonation time $1-4$ hours.

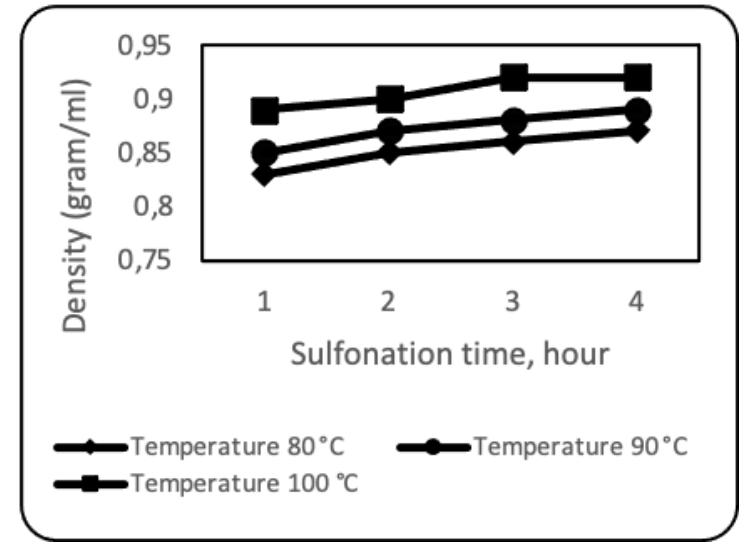

Figure 1. Effect of temperature and time of sulfonation on density

The density of MES increased with increasing temperature and sulfonation time. The density of MES at $100{ }^{\circ} \mathrm{C}$ is generally greater than the density of MES at temperatures below $\left(80^{\circ} \mathrm{C}\right.$ and $\left.90{ }^{\circ} \mathrm{C}\right)$. The increase in density value is also influenced by the sulfonation process time. The longer the sulfonation process, the greater the resulting MES density value. From the research it was concluded that the best density value in the sulfonation process occurred at 3 - 4 hours and a temperature of $100{ }^{\circ} \mathrm{C}$ with a density value of 0.92 gram $/ \mathrm{ml}$. This increase in density occurs because the binding of $\mathrm{SO}_{3}$ from sodium metabisulfite to the methyl ester structure increases so that the molecular weight increases.

The results of the analysis of variance showed that the temperature and duration of sulfonation had a significant effect on the density of MES. Based on Figure 6, the lowest density value occurs at a temperature of $80^{\circ} \mathrm{C}$ and a sulfonation time of 1 hour with a density value of $0.83 \mathrm{gr} / \mathrm{ml}$. This shows the effect of temperature and sulfonation time on the MES density value.

Increasing the density value is influenced by the size of the molecule and the intermolecular forces. The bonding of the $\mathrm{SO}_{3}$ sulfonate group to the metal ester makes the metal ester sulfonate (MES) tend to have a larger molecular size so that it has a higher density than the raw material. The low MES density value (0.83 gram $/ \mathrm{ml}$ ) at $80{ }^{\circ} \mathrm{C}$ and 1 hour sulfonation time indicates that the sulfonation reaction is not yet complete because the product is still mixed with metal esters. On the other hand, the MES resulting from sulfonation at a temperature of $100{ }^{\circ} \mathrm{C}$ with a sulfonation time of 180 - 240 minutes (3-4 hours) had a high density value indicating that the formation of MES was high, exceeding the yield at $90{ }^{\circ} \mathrm{C}$ and $80{ }^{\circ} \mathrm{C}$ 


\subsection{Effect of time and temperature on MES viscosity}

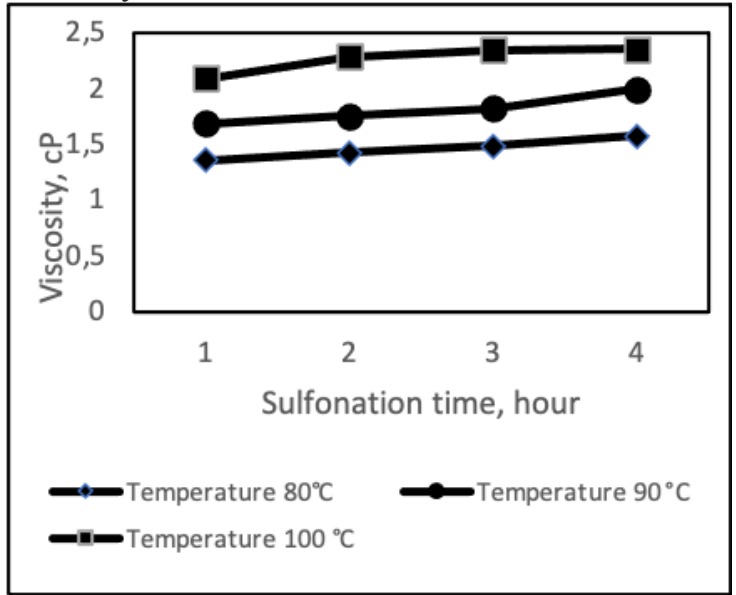

Figure2. Effect of temperature and time of sulfonation on viscosity

The methyl ester sulfonation process produces a product in the form of MES which is yellow in color with a higher viscosity than the thickness of the methyl ester used as the raw material. The increase in viscosity level can be used as an indicator that the methyl ester conversion has occurred during the sulfonation process into methyl ester sulfonate. The viscosity of a liquid or viscosity is a fluid characteristic that is influenced by the size of the molecules and the forces between molecules. The binding of the sulfonate group to the methyl ester makes MES have a larger molecular size so that it has a higher viscosity than its raw material (ME). The measurement results show that MES has a viscosity value of $1.35-2.35 \mathrm{cp}$ as shown in Figure 7. Figure 6. It appears that the overall graph tends to be positive linear in the temperature range $80-100{ }^{\circ} \mathrm{C}$ and sulfonation time of $1-4$ hours, where the viscosity increases with increasing temperature, so does the sulfonation time.

The viscosity of MES increases with increasing reaction time and temperature. The viscosity of MES at $100{ }^{\circ} \mathrm{C}$ is generally higher than the viscosity of the sulfonation products at temperature of $80{ }^{\circ} \mathrm{C}$ and temperature of $90{ }^{\circ} \mathrm{C}$. The increase in viscosity value is also influenced by the sulfonation time. The longer the sulfonation time, the greater the possibility of contact between substances so that the product has a high viscosity. This increase in viscosity occurs due to the binding of $\mathrm{SO}_{3} \mathrm{H}$ to the methyl ester structure. From the research, it was found that the best viscosity value from the sulfonation process occurred at 3-4 hours at $100{ }^{\circ} \mathrm{C}$ with a viscosity value of $2.34-2.35 \mathrm{cp}$.

The results of the analysis of variance showed that the mole ratio of the reactants and sulfonation time had a significant effect on the viscosity of MESA. Based on Figure 7, it is known that the viscosity value increases with the increase in sulfonation temperature and reaction time. The highest viscosity value was found in the MES sample which was sulfonated at a temperature of $100{ }^{\circ} \mathrm{C}$ and a time of 4 hours where the viscosity value was $2.35 \mathrm{cp}$. This shows that there is an effect of increasing temperature and sulfonation duration on the viscosity of MES or the formation of more MES.

Meanwhile, the sample at $80{ }^{\circ} \mathrm{C}$ conditions and 1 hour of sulfonation time had the lowest viscosity value of $1.35 \mathrm{cp}$, this was due to the sulfonation reaction that was not yet complete and the temperature was not optimal so that MES had not yet been formed. Therefore, the viscosity value is not too different from the raw material. On the other hand, the viscosity value at $100{ }^{\circ} \mathrm{C}$ and 4 hours was significantly different from the viscosity value at $80{ }^{\circ} \mathrm{C}$ operating condition and 1 hour time, as well as significantly different from the metal ester

\subsection{Effect of time and temperature on the degree of MES acidity}

Measurement of the $\mathrm{pH}$ value of the resulting MES aims to see the degree of acidity of the resulting surfactants at variations in temperature and sulfonation time. The results of MES $\mathrm{pH}$ analysis at various process operating conditions showed a range of values between 2.26-4.68 as shown in Figure 8. In this study the MES $\mathrm{pH}$ value decreased along with the higher temperature and the longer the sulfonation process. The resulting MES product is acidic, this is evidenced by its low value, namely 2.26-4.68. This acidic nature is due to the $\mathrm{H}+$ ions present in the $\mathrm{SO}_{3} \mathrm{H}$ group, so that the possibility of sulfonate groups forming in the methyl ester reactant is getting bigger, which is bound to ME along with the longer sulfonation time and the higher the sulfonation temperature. $\mathrm{Na}_{2} \mathrm{~S}_{2} \mathrm{O}_{5}$ which is used as reagent is a group of acid salts which are weak acids.

Based on Figure 8, it can be seen that the sulfonation temperature affects the value of the degree of acidity $(\mathrm{pH})$ of the resulting MES where the higher the sulfonation temperature, the $\mathrm{pH}$ value decreases with a tendency to follow a negative linear curve pattern. The MES $\mathrm{pH}$ value from the sulfonation temperature of $100{ }^{\circ} \mathrm{C}$. The overall observation time (1-4 hours) has a value that is much lower than the MES $\mathrm{pH}$ value resulting from sulfonation of $90{ }^{\circ} \mathrm{C}$ and also $80{ }^{\circ} \mathrm{C}$. Likewise with time, where the longer the sulfonation time of 1 the 4th hour, the $\mathrm{pH}$ value drops.

To anticipate that the $\mathrm{pH}$ of MES is not low, neutralization is carried out with the addition of $\mathrm{NaOH}$. The effect of adding the neutralization process can be seen from the research conducted by Adiandri (2010), where the $\mathrm{pH}$ of the MES before the neutralization process was 3-4 and after the neutralization process the $\mathrm{pH}$ increased to $7-8$.

When viewed from temperature, all $\mathrm{pH}$ values are different and even the longer the sulfonation time, the difference in $\mathrm{pH}$ values is very significant. When viewed from time alone, almost all of the $\mathrm{pH}$ values were significantly different except for the $\mathrm{pH}$ value between 3 hours and 4 hours of sulfonation. Meanwhile, if the two treatments are combined (temperature and sulfonation time), a very significant difference occurs in 
the treatment temperature of $100 \mathrm{C}-4$ hours against other treatments, namely $90 \mathrm{C}-2$ hours, $90^{\circ} \mathrm{C}-1$ hour, $80^{\circ} \mathrm{C}-2$ hours, and $80^{\circ} \mathrm{C}-1$ hour.

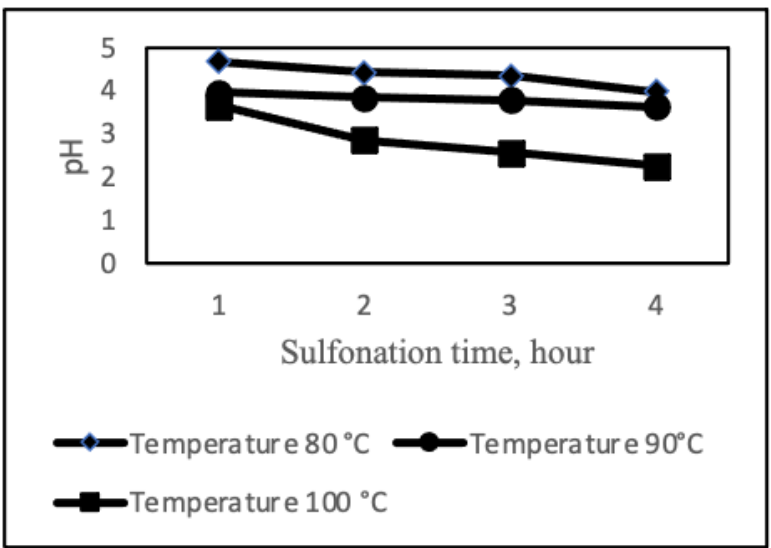

Figure 3. Effect of temperature and time of sulfonation on $\mathrm{pH}$

\subsection{Effect of sulfonation time and temperature on acid number}

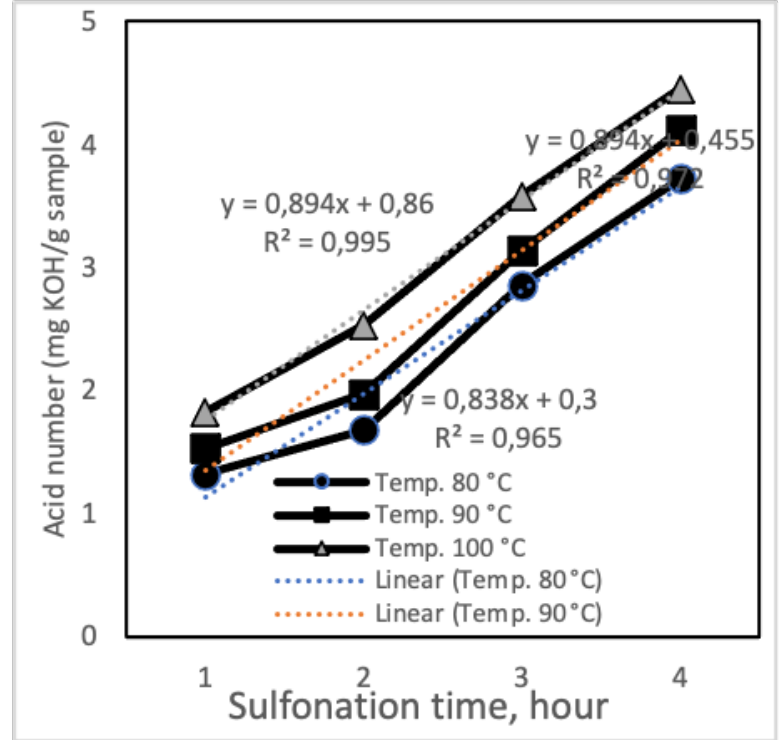

Figure 4. Graph of the relationship between sulfonation time and temperature and acid number

The acid number is a number that shows the number of milligrams of $\mathrm{KOH}$ needed to neutralize one gram of fat or oil. In Figure 9 it is clear that the three curves tend to increase in a positive linear manner where the longer the sulfonation time the acid number increases. This phenomenon is indicated by the three temperatures, both $80{ }^{\circ} \mathrm{C}, 90^{\circ} \mathrm{C}$, and $100^{\circ} \mathrm{C}$. Overall, the value of the degree of determination is R2 (the level of truth / confidence) of the three temperature relationship curves and the acid number for all temperatures $\left(80{ }^{\circ} \mathrm{C}, 90^{\circ} \mathrm{C}\right.$, and $\left.100^{\circ} \mathrm{C}\right)$ are above 0.95 (95\%) which means that the relationship between sulfonation time and acid number tends to be positive linear in the case of making metal ester sulfonate surfactants (MES) from CPO-based methyl esters.
If we compare the effect of temperature, the sulfonation curve at $100{ }^{\circ} \mathrm{C}$ is higher than the curve at $90^{\circ} \mathrm{C}$, and higher than the curve at $80^{\circ} \mathrm{C}$. This means that the overall value of the acid number at $100^{\circ} \mathrm{C}$ sulfonation is higher than the number value. acids at temperatures below $\left(90^{\circ} \mathrm{C}\right.$ and $80^{\circ} \mathrm{C}$ ). The lowest acid number is $1.32 \mathrm{mg} \mathrm{KOH} \mathrm{/} \mathrm{g}$ sample obtained at the sulfonation process temperature of $80^{\circ} \mathrm{C}$ and sulfonation time of 1 hour, on the other hand, the highest acid number value is $4.45 \mathrm{mg} \mathrm{KOH} / \mathrm{g}$ sample obtained at $100{ }^{\circ} \mathrm{C}$ sulfonation for 4 hours. Likewise, when viewed from time, the highest acid number value for all sulfonation temperatures was at 4 hours (Figure 4.2.).

\subsection{Effect of time and sulfonation temperature on iodine number}

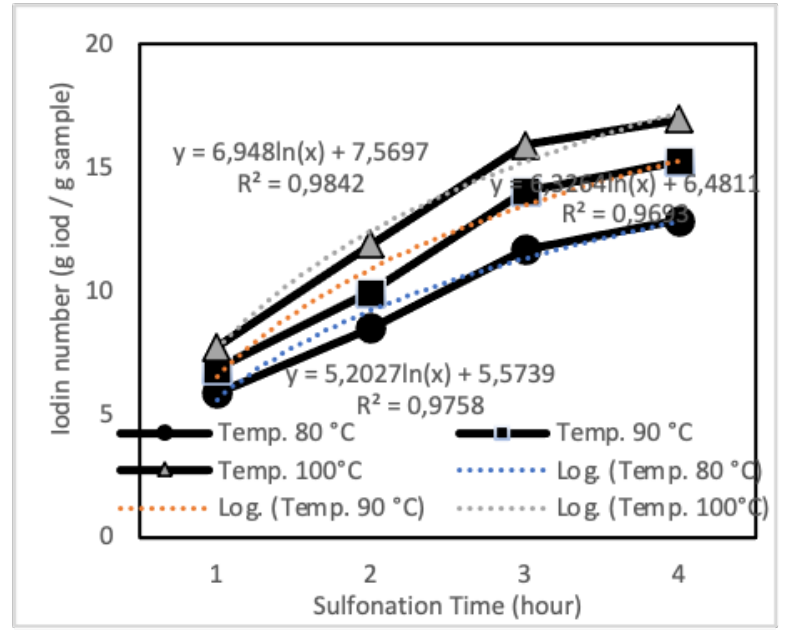

Figure 5. Graph of the relationship between sulfonation time and temperature to iodine number

The iodine number is often used to determine the amount of unsaturation in fatty acids. Unsaturation is in the form of double bonds, which will react with iodine compounds. The higher the iodine number, the more $\mathrm{C}$ $=\mathrm{C}$ bonds in the fat. Coconut oil is highly saturated, so it is best used in soap making.

In Figure 10 it is clear that the three trend curves increase positively linearly from the first hour to the third hour. This phenomenon is shown by the three temperatures, both $80{ }^{\circ} \mathrm{C}, 90^{\circ} \mathrm{C}$, and $100{ }^{\circ} \mathrm{C}$. After the third hour leading to the 4 th hour of sulfonation, even though the iodine number still rises but tends to slope (not upward) so that when viewed From the first hour to the fourth hour, the trend (trend) of the curve is logarithmic which is indicated by all values of the coefficient of determination $\left(\mathrm{R}^{2}\right)$ are above $95 \%$, which means that the level of truth is reliable. The trend of this logarithmic model was decided after several attempts with other trendlines such as linear, the value of $\mathrm{R}^{2}$ (coefficient termination / level of truth) was still smaller than the R2 value in the logarithmic equation above (Figure 10). 
When compared to the effect of temperature, the sulfonation curve at $100^{\circ} \mathrm{C}$ is higher than the curve at $90^{\circ} \mathrm{C}$, and higher than the curve at $80^{\circ} \mathrm{C}$. This means that the overall iodine value at $100^{\circ} \mathrm{C}$ sulfonation is higher than the number value. iodine at temperatures below $\left(80^{\circ} \mathrm{C}\right.$ and $90^{\circ} \mathrm{C}$ ). Likewise, if viewed from time, the highest iodine value for all sulfonation temperatures was at 4 hours. However, the difference in the value of iodine number at 3 hours and 4 hours of sulfonation is actually not significantly different where it can be seen on all curves that the ion number value tends to slope (not increase sharply) from hour 3 to hour 4 (Figure 10).

Based on Figure 10 above, it can be concluded that the highest iodine number is $16.92 \mathrm{~g}$ iod $/ \mathrm{g}$ of the sample obtained at a temperature of $100^{\circ} \mathrm{C}$ and a time of 4 hours of sulfonation. However, considering that the value of iodine number at the $3^{\text {rd }}$ hour for all sulfonation temperatures tends not to be significantly different from the iodine number at the 4 th hour, it is possible that the next experiment uses a time of 3 hours and is observed every 30 minutes to see the kinetic phenomenon.

\subsection{Surface tension testing on several MES samples}

Surface tension, which has units of dyne $/ \mathrm{cm}$, can be defined as the force per unit length applied parallel to the surface to compensate for the inward pull. Surface tension is one way of testing whether the methyl ester sulfonate that is made can function as a surfactant where each group of surfactant compounds will be able to reduce surface tension, reduce interface tension, and stabilize the emulsion because the surfactant can act as an emulsifier and demulsifier.

Meanwhile the interface voltage is the force per unit length present at the interface of two immiscible liquid phases. The interface tension is always less than the surface tension because the adhesive force of the two liquid phases forming an interface is greater than when a liquid phase and a gas phase are together. Thus, when the liquid is completely mixed, no interface tension occurs.

In this study, only the surface tension of four MES samples was measured which were obtained from the best conditions in the initial study. According to the curve in Figure 11, as the added concentration of MES in water increases, the surface tension decreases in a pattern that follows an exponential trend. In normal water without the addition of MES, the surface tension is 72 dyne $/ \mathrm{cm}$, then when each water sample is added MES 1 to MES 4 with a concentration of $0.2 \%$ to $1 \%$ by weight of the volume of water, the surface tension drastically decreases from $0 \%$ to $0.6 \%$. After that the decline curve is no longer sharp, tends to be stationary. This phenomenon occurs in all the MES samples added.

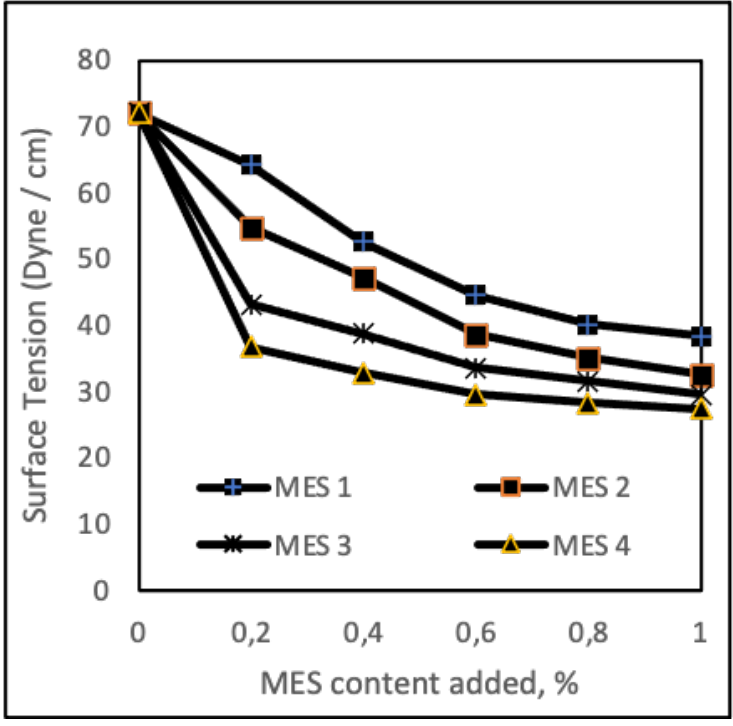

Figure 6. Graph of the relationship between MES levels and several MES samples to surface tension

When compared to the ability to reduce surface tension, the MES 4 sample shows the best adhesiveness in reducing surface tension where the lowest value is achieved at MES 4 and a concentration of $1 \%$ with a surface tension value of 27.4 Dyne $/ \mathrm{cm}$. When compared from all MES, the ability to reduce surface tension in order from the strongest to the weakest in this study is MES 4> MES 3> MES 2> MES 1 as visualized in Figure 11.

When compared with the added MES concentration, for all MES, the addition of $0.8 \%$ and $1 \%$ concentrations did not show a significant difference in the surface tension value, but the two concentrations gave very real values for surface tension to concentrations below $0.2 \%$. up to $0.6 \%$. Likewise, the concentrations of $0.2 \%, 0.4 \%$, and $0.6 \%$ each other give a real difference in the value of surface tension.

\subsection{Testing the stability of the emulsion of the MES made}

The surfactant can act as an emulsifier when two different phases can mix homogeneously because of the surfactant that is able to unite two phases with different degrees of polarity. Emulsion stability is measured between water and toluene. Toluene with water is mixed in a ratio of 6: 4 . The separation of the emulsion between toluene and water is measured based on the length of separation between the phases. The volume of each surfactant added was $1 \mathrm{ml}$. The separation time between the phases before adding the surfactant was compared to after adding the surfactant. The tool used to measure emulsion stability is a vortex mixer. 


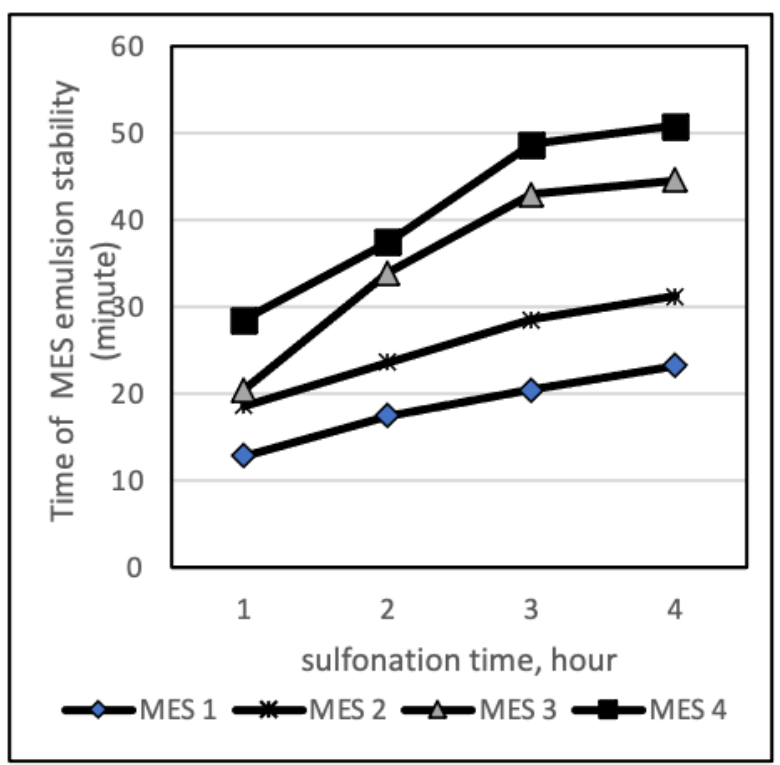

Figure 7. Graph of the relationship between sulfonation times and several MES samples to the length of the emulsion stability

Test the ability of the reaction product by measuring the duration of the stability of the oil-inwater emulsion. Stirring oil and water without the addition of the hydrogenated solution takes an average of 27 seconds, while with the addition of the hydrogenated solution, it can be seen that the heterogeneous mixture of toluene and water has turned homogeneous. The duration required from homogeneous to finally heterogeneous is what will be measured in this activity test.

The length of the MES emulsion stability ranged from 12.8 to 50.8 minutes. MES is able to maintain emulsion stability due to the influence of its hydrophilic and hydrophobic groups. The more MES formed, the higher the ability to maintain emulsion stability. The MES molecule contains a hydrophilic group in the form of -SO3- which can bind water while the hydrophobic group is a carbon chain from the methyl ester which can bind xylene. The more MES is formed, the more water and xylene are bound by the MES. The ability of MES to bind water and xylene results in a smaller interface tension between water and xylene. The graph of the relationship between various MES and sulfonation times on the emulsion stability value is presented in Figure 12.

The decrease in the interface tension of water and xylene indicates that the repulsion force between water and xylene is also decreasing. This also resulted in the emulsion system formed in the presence of MES being more stable so that the emulsion stability was higher.

From Figure 12 it can be seen that all MES can stabilize toluene and water emulsions, this indicates the presence of surfactants. It is also in accordance with the surface tension test that the more MES formed will result in lowering the surface tension and conversely increasing the emulsion stability.
Figure 12 shows that the longest duration is 50.8 minutes for the MES 4 surfactant product, which is at a temperature of $100{ }^{\circ} \mathrm{C}$ and a time of 4 hours. In the water toluene emulsion system, MES molecules will envelop the oil particles by binding them to hydrophobic groups to form globules. The globules will be dispersed in water to form an emulsion system. MES makes globules evenly dispersed by hydrogen bonds between the polar groups in MES and water. This condition makes the emulsion system stable (Adiandri, 2006).

Based on Figure 12 it can be concluded that the surfactants that have the ability to stabilize the emulsion are the MES 3 and MES 4 samples produced from the production process at a temperature of $90{ }^{\circ} \mathrm{C}-100{ }^{\circ} \mathrm{C}$ and a sulfonation time of $3-4$ hours where the length of the ability to stabilize the emulsion is between 42.9 minutes to 50.8 minutes.

\section{CONCLUSION AND SUGGESTION}

\subsection{Conclusion}

Based on the discussion of the results of research on the manufacture of Methyl Ester Sulfonate (MES) from palm oil-based methyl esters, it can be concluded that:

1. Characteristics of Methyl Ester Sulfonate Acid (MES) resulting from the sulfonation reaction, namely density 0.83-0.92 gr / $\mathrm{ml}$, viscosity $1.35-2.35 \mathrm{cp}$, and $\mathrm{pH} 2.26-4.68$

2. The temperature and time of sulfonation had a significant effect on the results of the analysis of methyl ester sulfonate (MES) analysis on the sulfonation reaction.

3. If the temperature is too high and the sulfonation time is too long, there is a tendency for the quality and quantity of MES to decrease due to the formation of by-products from MES in the form of salt compounds which can reduce the performance of the MES.

4. The best sulfonation conditions were obtained at a temperature of $100 \mathrm{C}$ and a sulfonation time of 4 hours with the resulting MES characteristics, namely iodine number $16.92 \mathrm{~g}$ iod / $\mathrm{g}$ sample, acid number $4.45 \mathrm{mg} \mathrm{KOH} / \mathrm{g}$ sample, surface tension 27.4 dyne $/ \mathrm{cm}$, and emulsion stability of 50.8 minutes.

\subsection{Suggestion}

To produce a better Methyl Ester Sulfonate (MES) surfactant, further research on catalysts and reactant ratios in the sulfonation process is needed. In addition, the treatment can still be varied in the bleaching process as well as the MES filtering and drying method in order to obtain a whiter MES product according to the standards. 


\section{ACKNOWLEDGMENT}

The authors would like to acknowledge the financial support from Polytechnic Negeri Sriwijya. Thank you also to the committee of the FIRST 2020 international conference

\section{REFERENCES}

[1] Alamanda. 2007. Pembuatan Metil Ester dari CPO untuk Surfactant Flooding. http://digilib.itb.ac.id/gdl.php? $\bmod =$ search. Diakses pada 17 Mei 2017

[2] Amri Q. 2009. "Surfaktan Metil Ester Sulfonat Guna Meningkatkan Recovery Minyak Bumi”. http://infosawit.com/ids/tekhnologi.pdf. Diakses pada 5 Mei 2017.

[3] Bergenstahl, 1997. Physicochemical Aspects of an Emulsifier Functionality. Didalam Food Emulsifier and Their Applications. Hasenhuetl, G.L. dan R.W. Hartel. (ed). Chapman \& Hall, New York

[4] Bernardini, E. 1983. Vegetable Oils and Fats Processing. Rome : Interstampa

[5] Foster, N.C. 1996. Sulfonation and sulfation process. The chemithon Corporation. 5430 West Marginal Way SW seattle, WA 98106 - USA Tel : (206) 9379954. Fax: (206)9323786. Email: chemoffice@,chemithon.com www.chemithon.com.

[6] Gunstone, F. D. 2004. The Chemistry of Oils and Fats: Sources, Composition, Properties and Uses. UK : Blackwell Publishing

[7] Hambali E, Mujdalifah. 2004. Teknologi Bioenergi. Jakarta : Agromedia Pustaka.
[8] Helianty, S dan Zulfansyah. 2011. Pembuatan Ester metilsulfonat dari ester metil Palm Stearin. Jurnal Teknobiologi. Vol.II: 37 -39

[9] Hidayati, Sri dkk. 2012. Optimasi Produk Metil Ester Sulfonat dari Metil Ester Minyak Jelantah. Tesis. Lampung : Universitas Lampung.

[10] Hovda. 1996. Sulfonation of Fatty Acid Ester. United States Patent. 5.587.500.

[11] Hui YH. 1996. Bailey's Industrial Oil and Fat Products. Edisi ke-5, volume ke-2. New York: John Willey \& Sons, Inc.

[12] Ketaren. 2005. Pengatur Teknologi Minyak dan Lemak Pangan. Jakarta: UI Press.

[13] Maharani. 2010. Pembuatan Metil Ester (Biodiesel) dari Minyak Dedak dan Metanol dengan Proses Esterifikasi dan Transesterifikasi. Skripsi. Semarang. Univetsitas Diponegoro. Matheson KL. 1996. Surfactant Raw Materials: Classification, Synthesis, and Use. Illinois:AOCS Pr.

[14] Pore, J. 1993. Oils and Fat Manual. Intercept Ltd, Andover, Uk, Paris :New York

[15] Sulastri, Yeni. 2010. Sintesis methyl ester sulfonic acis (mesa) dari crude palm oil (cpo) Menggunakan single tube falling film reaktor, (Online), http://fateta.ipb.ac.id/tin/images $/$, , /Yeni\%20sulastri_F351080121.doc $\underline{x}$ diunduh 13 Februari 2016

[16] Sheats, W.B dan B.W MacArthur. 2002. Methyl Ester Sulphonate Products: The Chemithon Corporation, USA

[17] Swern D. 1979. Bailey's Industrial Oil and Fat Products. Vol. I 4th Edition. John Willey and Son, New York. 